\author{
Associate professor Mihaela Cristina DRĂGOI*, PhD \\ E-mail: cristina.dragoi@ rei.ase.ro \\ The Bucharest University of Economic Studies \\ University assistant Maria-Floriana POPESCU, PhD \\ E-mail: maria.popescu@ rei.ase.ro \\ The Bucharest University of Economic Studies \\ Associate professor Jean Vasile ANDREI, PhD \\ E-mail: andrei_jeanvasile@yahoo.com \\ Petroleum-Gas University of Ploiesti \\ Associate professor Mihai MIEIL $\breve{A}, \mathbf{P h D}$ \\ E-mail: m_mieila@yahoo.com \\ Valahia University of Târgoviste

\section{DEVELOPMENTS OF THE CIRCULAR ECONOMY IN ROMANIA UNDER THE NEW SUSTAINABILITY PARADIGM}

Abstract: The transformation of the functional and highly competitive contemporary market economy paradigm and of the established economic structures has imposed the orientation and adoption of innovative, high-yielding and environmentally sustainable economic models, capable of generating both elevated levels of economic well-being and social protection. The multiplication and diversification of contemporary economic, social and environmental challenges forced important transformations of the economic paradigm. The limitations of the classic linear economic system have generated the emergence of new contemporary economic models, most often of hybrid type, which have significantly contributed to the conversion of classical production and consumption relations. The main objective pursued in this research is the identification of developments of the circular economy in Romania under the new sustainability paradigm using econometric methods. At the same time, the construction of an econometric model that adequately reflects the transformations generated by the process of transition to the circular economy in Romania was considered.

Key words: circular economy, energy productivity, economic paradigm domestic material consumption, sustainable development.

JEL Classification: C10; O11; P17; Q56.

* Corresponding author

DOI: $10.24818 / 18423264 / 52.2 .18 .08$ 
Mihaela Cristina Drăgoi, Maria-Floriana Popescu, Jean Vasile Andrei, Mihai Mieilă

\section{Introduction}

The modernisation and transformation of the contemporary economy, centred on high effectiveness levels and increased efficiency, based on the functionality and the competitive dynamics of the free-market and its orientation towards a sustainable dimension in attracting and using resources, constitutes a decisive objective in establishing a more circular economy. At the same time, the available literature (Kalmykova, Sadagopan and Rosado, 2017; Martins, 2018) has identified the risk that using the concepts promoted and applied within the new paradigm of the sustainable economy can lead to the development of economic models that do not always share the characteristics of sustainability, but are often a deviation of certain new economic models that distort the competitive environment, with negative effects on employment and on drawing economic resources into production.

The model of the contemporary market economy is experiencing a broad process of innovation and development of new economic models with various objectives and implications upon existing economic paradigms, but which often seek to create multiple values. Economic theory has been enriched with several new economic concepts and models such as: circular economy, digital economy, integrative economy, participatory economy, economy of common well-being or economy of functionality.

The development of the circular economy creates the necessary general framework in order to obtain positive economic effects for enterprises and entrepreneurs. By applying the principles of circular economy, high energy efficiency and energy savings can be achieved, attracting and reusing waste within the technological processes, creating new durable jobs and opportunities to integrate into the economic circuit a range of resources otherwise considered abandoned. Thus, the circular economy model finds itself in a continuous transformation, reinventing itself where needed, promoting instruments and practices that are not always specific, in order to integrate and capitalise long-term potential and to create indivisible and permanent connections between sustainability and the economic well-being of the population.

Circular economy can be a vector for the promotion and coagulation of triggering factors for economic growth, investment and industrial innovation. This involves moving from the classical approach of the linear economic system towards attracting into production resources with potential for reuse and regeneration, with high yield levels. The circular economy brings into context a new approach to the classical economic system centred on a linear economy such as extractiontransformation-use-disposal (Kirchherr, Reike and Hekkert, 2017) and the implementation of a new way of using waste that can be transformed into new resources attracted to the economic circuit. Thus, Korhonen, Honkasalo and Seppälä

DOI: $10.24818 / 18423264 / 52.2 .18 .08$ 
Developments of the Circular Economy in Romania under the New Sustainability Paradigm

(2018), when analysing the concept of circular economy, state that it is often perceived as a collection of vague and separate ideas with multidisciplinary affiliation.

Circular economy is a broad concept which comprises aspects from natural capitalism (Lovins, Hawken and Lovins, 2008), ecological efficiency (Huppes and Ishikawa, 2009), socio-ecological resilience (Crépin et al., 2012) to industrial ecology (Lifset and Graedel, 2002) and circular business models (Lewandowski, 2016).

Transforming the paradigm of the contemporary functional and extremely competitive market economy requires an ample and long process of transition and adaptation to the new environmental, ecological, social and functional requirements which involve the development of new more environmental-friendly and energy efficient economic typologies. The achievement of the objectives of the circular economy entails an in-depth understanding of the mechanisms and determinants of functioning of the economy as a whole, in the process of reaching the sustainability of the internal functioning structures. The development of the circular economy is a possible response to the increase of the economic competitiveness by re-using and reattracting into production various economic resources with available potential.

\section{Data and material preliminaries}

In order to achieve the set and assumed objectives of the current research, specific indicators were used, for which data sets were available for a period longer than at least ten years so as to describe and understand several specific transformations and evolutions that may be circumscribed to the concept of circular economy. Nine variables considered to be representative to the concept were taken into account, using the latest data sets available on the Eurostat web portal (Eurostat, 2017) on issues such as: domestic material consumption, energy productivity, greenhouse gas emissions, resources productivity, municipal waste recycling rate, water productivity and water exploitation index, indicators aimed at assessing the sustainability of the current national economic paradigm and the potential for the development of a circular economy in Romania.

Table 1 presents the description of the variables referring to Romania, based on the data series taken into consideration, with their measurement units and related symbols for the period $2000-2015$ or 2016, according to data availability.

Table 1. Description of variables used in research

\begin{tabular}{|c|c|c|}
\hline Symbol & Variables & Data availability \\
\hline Dmc & Domestic material consumption (tons per capita) & $2000-2016$ \\
\hline e_pty & Energy productivity (in EUR per kg oil equivalent) & $2000-2015$ \\
\hline Ghg_e & Greenhouse gas emissions (tons of $\mathrm{CO}_{2}$ equivalent per capita) & $2000-2015$ \\
\hline & Annual growth rate of national nominal net product & $2000-2015$ \\
\hline$n v \_t x_{-} r e v$ & Total budget revenue from environmental taxes ( $\%$ of GDP) & $2000-2015$ \\
\hline
\end{tabular}

DOI: $10.24818 / 18423264 / 52.2 .18 .08$ 
Mihaela Cristina Drăgoi, Maria-Floriana Popescu, Jean Vasile Andrei, Mihai Mieilă

\begin{tabular}{l|lc}
\hline \multicolumn{1}{c|}{ Symbol } & \multicolumn{1}{c}{ Variables } & Data availability \\
\hline $\boldsymbol{r}$ ppty & Resources productivity (EUR per kg) & $2000-2016$ \\
rec_rate & Municipal waste recycling rate $(\%)$ & $2000-2015$ \\
$\boldsymbol{w}$ pty & Water productivity (Purchasing Power Standard (PPS) $\left./ \mathrm{m}^{3}\right)$ & $2000-2015$ \\
wei & Water exploitation index $(\%-$ surface and phreatic water) & $2000-2015$ \\
\hline
\end{tabular}

Source: Eurostat (2017)

The results of the statistical processing of the data series presented above and the details of the related descriptive statistics are presented in Table 2.

Table 2. The main statistical indicators of the data series

\begin{tabular}{|c|c|c|c|c|c|c|c|c|c|}
\hline & $d m c$ & e_pty & ghg_e & $\begin{array}{c}n v_{-} t x_{-} \\
r e v\end{array}$ & $r_{\_} p t y$ & $n n i$ & rec_rate & $w_{\_}$pty & $w e i$ \\
\hline Mean & 18.357 & 6.144 & 6.489 & 2.178 & 0.321 & 10.756 & 5.519 & 34.488 & 18.056 \\
\hline Median & 20.153 & 6.15 & 6.445 & 2.065 & 0.311 & 6.578 & 1.7 & 36.35 & 17.85 \\
\hline Maximum & 26.843 & 10.1 & 7.16 & 3.38 & 0.4811 & 33.836 & 14.8 & 50.6 & 21.9 \\
\hline Minimum & 7.684 & 3.2 & 5.79 & 1.75 & 0.2494 & -16.721 & 0 & 14.5 & 14.6 \\
\hline Std. Dev. & 5.295 & 2.310 & 0.480 & 0.379 & 0.050 & 13.187 & 6.129 & 11.450 & 1.942 \\
\hline Skewness & -0.386 & 0.214 & -0.054 & 2.034 & 2.046 & 0.048 & 0.521 & -0.422 & -0.069 \\
\hline Kurtosis & 2.179 & 1.725 & 1.527 & 7.436 & 7.981 & 2.996 & 1.342 & 1.975 & 2.745 \\
\hline Jarque-Bera & 0.847 & 1.206 & 1.454 & 24.148 & 27.705 & 0.005 & 2.556 & 1.177 & 0.056 \\
\hline Probability & 0.655 & 0.547 & 0.483 & 0.000 & 0.000 & 0.997 & 0.279 & 0.555 & 0.972 \\
\hline Sum & 293.71 & 98.3 & 103.8 & 34.84 & 5.137 & 150.58 & 88.3 & 551.8 & 288.9 \\
\hline Sum Sq.Dev. & 420.57 & 80.02 & 3.452 & 2.153 & 0.037 & 2261 & 563.4 & 1966.68 & 56.58 \\
\hline Obs. & 16 & 16 & 16 & 16 & 16 & 14 & 16 & 16 & 16 \\
\hline
\end{tabular}

Source: authors' own processing

The information in Table 2 is complemented by the graphical representation of the evolution of the variables considered in the research, for the period under analysis, which is described in Figure 1. 
Developments of the Circular Economy in Romania under the New Sustainability Paradigm
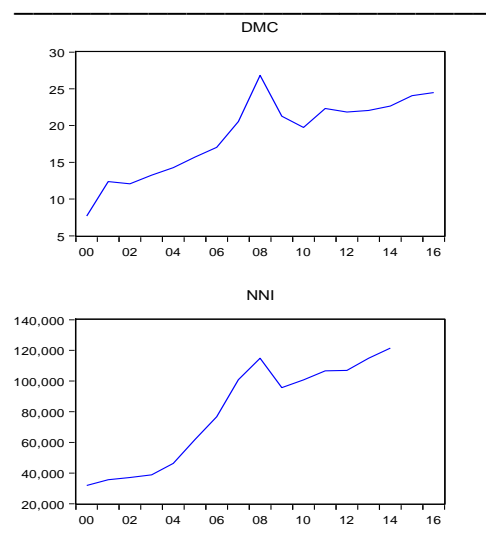

REC_RATE

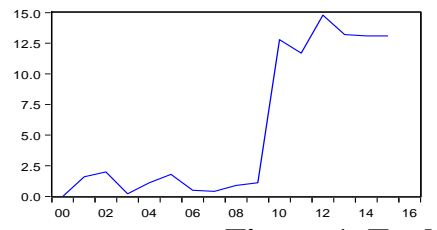

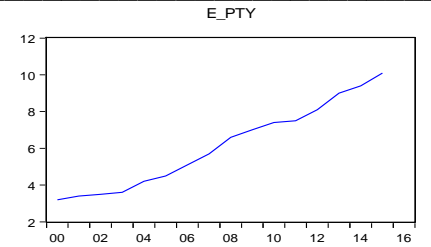

NV_TX_REV

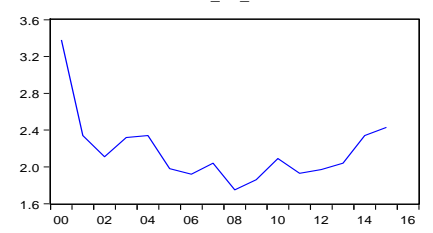

W_PTY

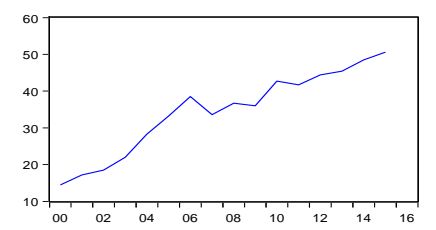

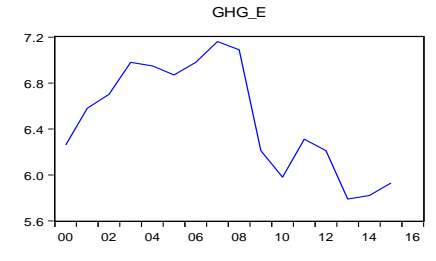

R_PTY

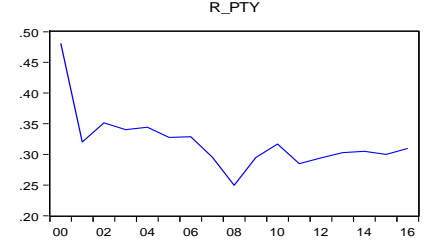

WEI

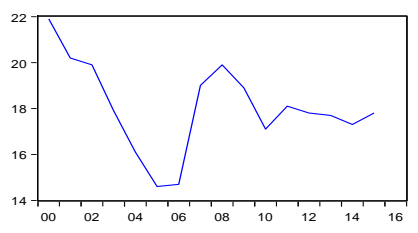

Figure 1. Evolution of the variables considered in research

Source: authors' own processing

\section{Research methodology}

Starting from the specificity and the theoretical dimensions of the circular economy, identifying and applying an appropriate research method are a delicate and topical endeavour. The construction of an econometric model that closely reflects the transformations generated by the process of transition to the circular economy in Romania and the possibility of its implementation in the national economy is one of the fundamental objectives of this research.

Given the complexity of modelling an appreciable number of variables, the time intervals and the research specificity, a co-integrative approach is required to identify and highlight a long-term equilibrium relationship between a set of nonstationary variables taken into consideration for this research. The rather high probability of the endogeneity of the set of variables was considered, which may involve a causal relationship of the type defined by Granger, Huangb and Yang (2000). In this context, the use and application of Granger causality tests are the most appropriate instrument for co-integration techniques, both to examine and highlight the short and long term relationships between the variables considered in the model (Granger, Huangb and Yang, 2000), but also to observe the Error Correction Mechanism (ECM).

DOI: 10.24818/18423264/52.2.18.08 
In order to test the existence and manifestation of the causality relationship between the variables used in defining the model, the three-step classical method was also used. Therefore, in the first stage, the evaluation of the order of integration of the data series was carried out by applying the unit root tests, followed in the second stage by the causality and co-integration tests described by Engle \& Granger (1987); the third step was to perform the actual co-integration analysis as a technique for observing the existence of a long-term stable relationship between the variables contained in the set under analysis by applying a Vector Autoregressive (VAR) model.

As in other previous researches (Popescu et al., 2018), the tests described by Levin, Lin and James Chu (2002), known as the LLC test and by Im, Pesaran and Shin (2003), respectively the IPS test, were employed for assessing the existence of the unit root. As a remark, in both tests, the null hypothesis claims the presence of the unit root (either common, for LLC, or for part of the series, in the case of IPS) against the stationary alternative. The resulting autoregressive model is one of the form described in equation (1) with the same meanings as in previous works (Pesaran, 2007; Apergis and Payne, 2010).

$\Delta y_{i t}=\rho y_{i, t-1}+\sum_{L=1}^{p i} \theta_{i L} \Delta y_{i, t-L}+\delta X^{\prime}{ }_{i t}+\varepsilon_{i t}$

As argued in other specialised studies (Choi, 2001; Abdullah and Morley, 2014), both LLC and IPS tests require separate Augmented Dickey-Fuller (ADF) regressions for each series, amended by the fact that in the case of LLC the null hypothesis assumes the existence of a common non-stationary process, identical for all series, against the alternative hypothesis, which implies the absence of the unit root, while in the case of LLC the specific homogeneity restriction is relaxed, allowing the value of the coefficient $y_{i, t-1}$ to differ among the considered series; testing is conducted

using $t$ statistics, namely the tests of the ADF unit roots of the series, applying equations (2) - (4) as in Popescu et al. (2018), taking into account the amendments already highlighted in previous literature (Im, Pesaran and Shin, 2003; Im, Lee and Tieslau, 2010):

$$
\bar{t}=\frac{\sum_{i=1}^{N} t_{\rho i}}{N}
$$

where $t_{\rho i}$ describes the value of the $t$ statistics for each series. In this case, the alternative hypothesis is defined by equation (3):

$$
H_{1}:\left\{\begin{array}{l}
\rho_{i}<0, i=\overline{1, N_{1}} \\
\rho_{i}=0, i=\overline{N_{1}+1, N}
\end{array}\right.
$$

which implies the existence of a non-zero fraction of the stationary cross sections.

\section{0}

DOI: $10.24818 / 18423264 / 52.2 .18 .08$ 
Developments of the Circular Economy in Romania under the New Sustainability Paradigm

$$
\lim _{N \rightarrow \infty}\left(\frac{N_{1}}{N}\right)=\gamma, 0<\gamma<1
$$

At the same time, causality is observed and emphasised by applying the procedure described by Engle and Granger (Engle and Granger, 1987) by using the Vector Error Correction Model (VECM) in two phases, while the long-term equilibrium relationship is highlighted based on the Error Correction Term (ECT). In this research also, the Generalised Method of Moments (GMM) was used, derived from previous considerations available in Arellano and Bover (1995) and Bond (2002), specifying a model of the form below:

$$
\begin{aligned}
& \Delta d m c_{t}=\alpha^{d m c}+\beta^{d m c} E C T_{t-1}^{d m c}+\sum_{j=1}^{m} \delta_{j}^{d m c} \Delta d m c_{t-j}+\sum_{s=1}^{q} \gamma_{1, s}^{d m c} \Delta e p t y_{t-s}+\ldots+\sum_{s=1}^{v} \gamma_{9, s}^{d m c} \Delta w e i_{t-v}+u_{t} \\
& \Delta e_{-} p t y_{i, s}=\alpha_{i}^{e-p t y}+\beta^{e-p t y} E C T_{t-1}^{e-p t y}+\sum_{j=1}^{m} \delta_{j}^{e-p t y} \Delta d m c_{t-j}+\sum_{s=1}^{q} \gamma_{1, s}^{w e i} \Delta e p t y_{t-s}+\ldots+\sum_{s=1}^{v} \gamma_{9, s}^{w e i} \Delta w e i_{t-v}+w_{t}
\end{aligned}
$$

Moreover, it was also considered that in the general context of the VAR models, one of the important aspects is given by the type of response to exogenous shocks of the investigated system. These effects are defined as innovations in current and future values of the endogenous variables. If innovations are not simultaneously correlated, interpreting the impulse response is immediate. The evaluation of impulses is based on the application of a $P$ transformation in the structure of the innovations so that they become uncorrelated, as in equation (6):

$v_{t}=P \mu_{t} \sim(0, D)$

where $D$ represents the covariance matrix (diagonal).

The present research is based on various other existing studies such as the ones of Apergis and Payne (2010), Abdullah and Morley (2014), Popescu et al. (2018) and the results presented in the following section are relevant for this field of research.

\section{Results and discussion}

The results of the IPS and LLC unit root tests for the considered series are presented in Table 3. According to these findings, except for the weight of environmental taxes in the GDP and resources productivity, which are stationary, all the variables in the analysed set contain a unit root. Consistent with the methodological explanations within the previous section, since two of the data series are stationary, the IPS test result shows the stationarity of the group of variables under consideration. At the same time, the result of the LLC test performed for the set of variables shows the presence of first-order integration. In this context, it is worth mentioning that the generally superior reliability of the IPS test results compared to the ones of LLC test (Baltagi, 2005, pp. 242-243) is emphasised in the specialised literature.

\section{1}

DOI: $10.24818 / 18423264 / 52.2 .18 .08$ 
Mihaela Cristina Drăgoi, Maria-Floriana Popescu, Jean Vasile Andrei, Mihai Mieilă

Table 3. The results of IPS and LLC unit root tests

\begin{tabular}{|c|c|c|}
\hline Variable & Level & Differenced \\
\hline$d m c$ & -2.012 & $-4.421 * * *$ \\
\hline e_pty & 1.579 & $-2.870^{*}$ \\
\hline $\overrightarrow{g h g \_e}$ & -0.994 & $-3.587 * *$ \\
\hline$n v \_t x_{-} r e v$ & $-5.610 * * *$ & $-5.326 * * *$ \\
\hline$p c \_n n i$ & -2.009 & $-3.623 * *$ \\
\hline$r_{-} p t y$ & $-6.344 * * *$ & $-3.418 * *$ \\
\hline rec_rate & -0.808 & $-4.295 * * *$ \\
\hline w_pty & -1.126 & $-2.876^{*}$ \\
\hline $\overrightarrow{w e i}$ & -2.929 & $-2.707^{*}$ \\
\hline W-stat & $-2.282 * * *$ & $-6.500 * * *$ \\
\hline LLC group tes & 1.029 & $-7.853 * * *$ \\
\hline
\end{tabular}

Note: The lag length determined using the Schwartz information criterion. All test equations include the individual constant term ("fixed effects").

***, **, * Indicate the rejection of the null hypothesis of existence of the unit root for significance thresholds of 1,5 and $10 \%$, respectively (unilateral test).

The significant results of the Granger causality tests applied in the case of the pairs of analysed series are presented in Table 4. According to the approach provided by Granger et al. (2000), testing of the co-integrative process is performed two-way, meaning that each variable is acting as a dependent variable.

Table 4. Significant results of Granger causality tests

\begin{tabular}{|c|c|c|c|c|c|c|c|c|c|}
\hline Variable & $d m c$ & e_pty & Ghg_e & $n v \_t x \_r e v$ & $n n i$ & $r \_p t y$ & rec_rate & W_pty & wei \\
\hline$d m c$ & - & & $6.44^{* * *}$ & & & & $6 . \overline{5} 7^{* *}$ & & \\
\hline e_pty & & & & & & & $5.32^{* *}$ & & \\
\hline ghg_e & & $4.45^{* *}$ & & & & & $4.87^{* *}$ & & \\
\hline$n v \_t x_{-} r e v$ & & & & & & $3.96^{*}$ & & & \\
\hline$n n \bar{i}$ & $15.99^{* * * *}$ & & $5.39^{* *}$ & & & $7.97^{* * *}$ & $16.17^{\text {**** }}$ & & \\
\hline $\begin{array}{l}r \_p t y \\
\text { rec_rate }\end{array}$ & & & $10.00^{* * * *}$ & & $5.65^{* *}$ & & & & \\
\hline$w \_\overline{p t y}$ & $6.78^{* * *}$ & $4.10^{*}$ & & & $11.30^{* * *}$ & & & & \\
\hline $\overrightarrow{w e i}$ & $9.23^{* *}$ & $3.86^{*}$ & & & $12.36^{* * * *}$ & $8.49^{* * * *}$ & & $4.81^{* *}$ & \\
\hline
\end{tabular}

Note: In the first column, the explanatory variable in the causality relation; table head dependent variable.

$* * *, * *, *$ Indicate the rejection of the null hypothesis of absence of causality for a significance threshold of 1, 5 and $10 \%$, respectively.

The obtained results suggest that all the variables under analysis may be in a co-integration relationship. However, for some of these variables interesting observations can be made, as follows: energy productivity acts as an exogenous 
Developments of the Circular Economy in Romania under the New Sustainability Paradigm

variable only for the municipal waste recycling rate; water productivity acts as an exogenous variable for domestic material consumption, energy productivity and the annual growth rate of national nominal net product and is an endogenous variable only in relation to the water exploitation index; the latter is in a co-integration relationship as an exogenous variable with five of the other eight variables considered without being influenced by any of these. Also, another study conducted by Andrei et al. (2016) points out that there is a correlated approach to economic growth represented either by the level of GDP per capita or by the annual growth rate of national nominal net product, on a case by case basis, and the energy consumption, by using the ratio between these two variables (through energy intensity and energy productivity indicators respectively). Contrary to these approaches, the results obtained are aligned with those highlighted by researches in this field within the European Union, which express a decoupling of the two indicators (Popescu et al., 2018).

Additionally, in order to verify a possible co-integration relationship between the variables, the specific tests described by Engle and Granger (1987) and Phillips and Ouliaris (1990) and already established in some specialty studies (Abdullah and Morley, 2014; Popescu et al., 2018) have been used, the results of which are presented in Tables 5 and 6.

Table 5. The results of the Engle-Granger co-integration test

\begin{tabular}{|c|c|c|c|c|c|c|}
\hline \multirow{3}{*}{ Variable } & \multicolumn{6}{|c|}{ Trend specification } \\
\hline & \multicolumn{2}{|c|}{ Absent } & \multicolumn{2}{|c|}{ Fixed effects } & \multicolumn{2}{|c|}{ Linear trend } \\
\hline & $\tau$-stat & $z$-stat & $\tau$-stat & $z$-stat & $\tau$-stat & $z$-stat \\
\hline$d m c$ & -4.384 & -16.69 & -4.285 & -16.44 & -3.913 & $-34.50^{* * * *}$ \\
\hline e_pty & -3.054 & $73.98^{* * *}$ & -3.264 & $82.04^{* * * *}$ & -3.383 & $-13.15^{*}$ \\
\hline $\overrightarrow{g h g} \_$ & -3.430 & -13.02 & -3.793 & -28.85 & -3.862 & $46.65^{* * *}$ \\
\hline$n v \_t x_{-} r e v$ & $-7.402^{* *}$ & $-88.43^{* * * *}$ & $-7.244 *$ & -80.51 & -4.727 & $54.85^{* * * *}$ \\
\hline$n n \bar{i}-$ & -4.358 & -16.497 & $-7.487^{* *}$ & -22.74 & $-7.488 *$ & -22.74 \\
\hline$r_{\perp} p t y$ & -5.748 & $-37.95^{* * *}$ & -5.748 & -37.64 & -5.686 & $-44.87^{* * *}$ \\
\hline rec_rate & -4.206 & -16.414 & -5.276 & -19.36 & -6.106 & -20.97 \\
\hline$w \_\overline{p t y}$ & -4.188 & -16.071 & $-7.002 *$ & -22.13 & -6.448 & -21.33 \\
\hline wei & -3.641 & -14.134 & -6.407 & -21.26 & -5.788 & -20.16 \\
\hline
\end{tabular}

Note: The lag length determined using the Schwartz information criterion.

***, **, * Indicate the rejection of the null hypothesis of absence of co-integration for a significance threshold of 1, 5 and $10 \%$, respectively (unilateral test).

Table 6. The results of the Phillips-Ouliaris co-integration test

\begin{tabular}{|c|c|c|c|c|c|c|}
\hline \multirow{3}{*}{ Variable } & \multicolumn{6}{|c|}{ Trend specification } \\
\hline & \multicolumn{2}{|c|}{ Absent } & \multicolumn{2}{|c|}{ Fixed effects } & \multicolumn{2}{|c|}{ Linear trend } \\
\hline & $\tau$-stat & $z$-stat & $\tau$-stat & $z$-stat & $\tau$-stat & $z$-stat \\
\hline$d m c$ & -4.626 & $-14.56^{* *}$ & -4.524 & $-14.15^{* *}$ & -4.006 & -13.30 \\
\hline e pty & -3.286 & -12.67 & -2.970 & -11.24 & -3.378 & $-12.81 *$ \\
\hline $\overrightarrow{g h g \_e}$ & -3.429 & -12.76 & -3.009 & $-10.42^{* * *}$ & -3.165 & $-12.25^{* *}$ \\
\hline$n v \_t x_{-} r e v$ & $-7.697^{* *}$ & -16.51 & $-7.229 *$ & -16.16 & $-7.371^{*}$ & -16.27 \\
\hline
\end{tabular}

133

DOI: $10.24818 / 18423264 / 52.2 .18 .08$ 
Mihaela Cristina Drăgoi, Maria-Floriana Popescu, Jean Vasile Andrei, Mihai Mieilă

\begin{tabular}{lllllll}
\hline nni & -4.481 & -15.16 & $-9.109^{* * *}$ & -20.90 & $-9.110^{* *}$ & -20.90 \\
r_pty & $-7.223^{* *}$ & -20.64 & $-7.201^{*}$ & -20.62 & $-7.967^{* *}$ & -20.79 \\
rec_rate & -4.300 & -14.97 & -5.538 & -18.03 & -6.591 & -19.60 \\
$\boldsymbol{w}$ pty & -4.261 & -14.96 & $-7.884^{* *}$ & -20.69 & $-7.172^{*}$ & -19.78 \\
wei & -3.648 & -13.43 & $-7.057^{*}$ & -19.80 & -6.348 & -18.45 \\
\hline ***, **, * Indicate the rejection of the & null hypothesis of absence of co-integration for a \\
significance threshold of 1, 5 and 10\%, respectively (unilateral test).
\end{tabular}

By analysing the results presented in Tables 5 and 6 , we observe that for different trend specifications, with the exception of the municipal waste recycling rate and, by extension, the water exploitation index (which reports only one significant result for the significance threshold of $10 \%$ ), for all other series, the null hypothesis of absence of co-integration is rejected with at least two relevant results for the significance threshold of $5 \%$ (excluding water productivity, with a significant result for $5 \%$ and two significant results for the $10 \%$ significance threshold respectively). As a result, the exogenous characteristic of the municipal waste recycling rate and the water exploitation index can be considered, with the inclusion of the ECT in the VEC model. Table 7 presents the results of the VEC model estimate and of the implicit term based on the Arellano-Bover' GMM approach.

Table 7. Estimating the Error Correction Term in the Vector Error Correction Model

\begin{tabular}{|c|c|c|c|c|c|}
\hline \multirow{2}{*}{ Variable } & \multirow{2}{*}{$\begin{array}{c}\text { ECT coefficient } \\
(t \text {-stat })\end{array}$} & \multirow{2}{*}{$\begin{array}{l}\text { Adjustment speed } \\
(t \text {-stat })\end{array}$} & \multicolumn{3}{|c|}{$\begin{array}{l}\text { Lag coefficient } \\
\text { (t-stat) }\end{array}$} \\
\hline & & & $d m c$ & e_pty & ghg_e \\
\hline$d m c$ & 1.00 & $-1.64(-17.67)^{* * *}$ & $0.36(3.21)^{* * *}$ & $-0.072(-0.81)$ & $0.10(1.34)$ \\
\hline e_pty & $-1.883(-15.91)^{* * *}$ & $0.044(0.58)$ & $-3.66(-5.32)^{* * *}$ & $0.15(0.27)$ & $-0.86(-1.92)$ \\
\hline ghg_e & $-3.351(-21.16)^{* * *}$ & $-0.20(-3.32)^{* * * *}$ & $-4.52(-4.56)^{* * *}$ & $0.87(1.08)$ & $-1.07(-1.65)$ \\
\hline$r_{\text {ppty }}$ & & & $-93.5(-21.33)^{* * * *}$ & $0.092(0.026)$ & $-8.66(-3.02)^{* * * *}$ \\
\hline rec_rate & & & $-0.06(-2.17)^{* *}$ & $-0.034(-1.422)$ & $0.032(2.45)^{* *}$ \\
\hline$w \_\overline{p t y}$ & & & $0.06(3.598)^{* * * *}$ & $0.032(2.45)^{* *}$ & $-0.008(-0.81)$ \\
\hline$w e i$ & & & $0.029(6.94)^{* * *}$ & $0.008(0.249)$ & $0.006(0.23)$ \\
\hline
\end{tabular}

Note: Lag length: $1,1$.

***, ** Indicate the meaning of the estimator for significance thresholds of 1 and 5\%, respectively.

Figure 2 represents graphically the responses to the impulse (innovations) of the endogenous variables, according to the methodology presented beforehand, in which the value of the impulse is given by the standard deviation of the residual variable. 
Developments of the Circular Economy in Romania under the New Sustainability Paradigm

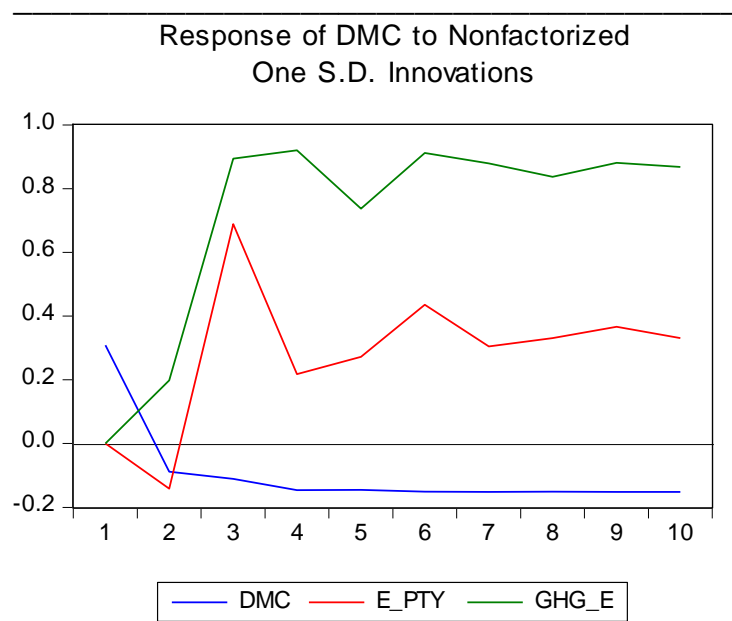

Response of E_PTY to Nonfactorized One S.D. Innovations

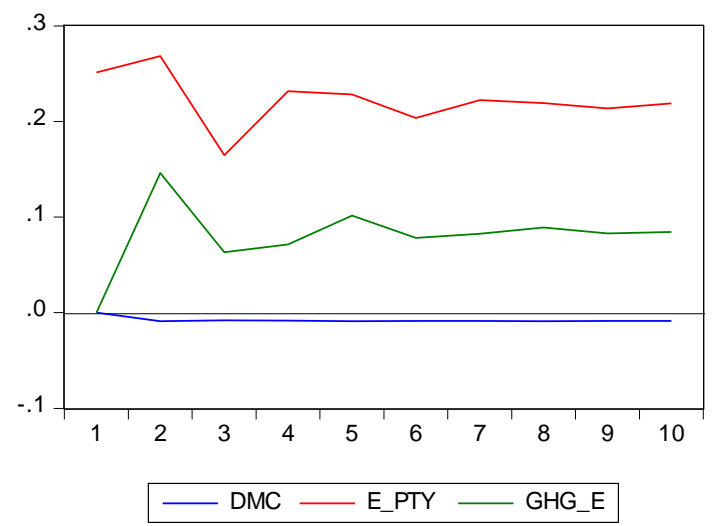

Response of GHG_E to Nonfactorized

One S.D. Innovations

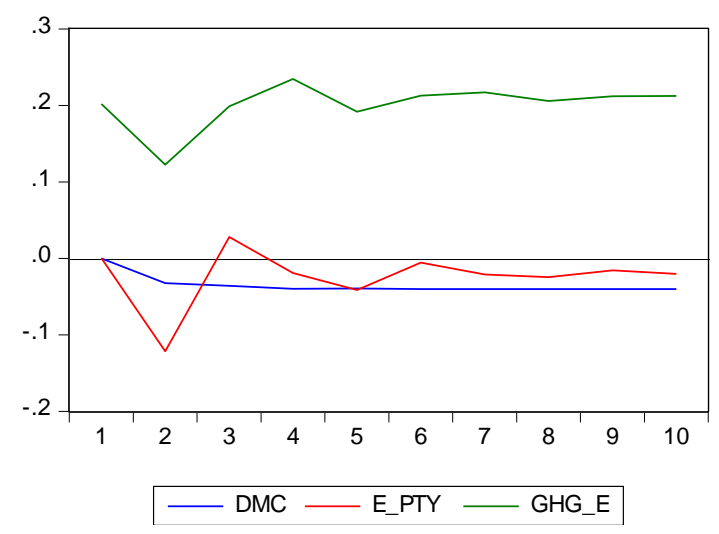

Figure 2: Responses to innovations of endogenous variables - the impulse's value is equal to the standard deviation of the generating variable

Source: authors' own processing

The significant results of the ECT estimate highlight the trend of overtargeting the long-term equilibrium both in the case of energy productivity and greenhouse gas emissions; this latter variable, alongside domestic material consumption, reports significant outcomes in the short-term causal effect. All these

DOI: $10.24818 / 18423264 / 52.2 .18 .08$ 
coefficients bear the negative sign, which means that the action of the three variables within the co-integration equation is in the direction of ensuring system stability. Also, within the estimation equation of the domestic material consumption the significance of all the coefficients of both the endogenous and the exogenous variables is observed, while the energy productivity supports the significant influence of water productivity. An interesting result is that greenhouse gas emissions are significantly influenced by the resources productivity with which they are negatively correlated and by the recycling rate of municipal waste, with direct correlation.

\section{Conclusions}

The social economy constitutes a subject of extremely current but at the same time controversial research, by the dimensions and the effects it generates at macroeconomic level, as well as from the perspective of conceptual definition and delimitation, incorporating a series of practices and notions which it presumes. Although, as a result of the conducted analysis, we found that all the variables considered in this study are in a co-integration relationship, the obtained findings arouse interest through the described situations.

Thus, in the case of certain variables used for this analysis, an interesting behaviour can be noticed. In the present case, the energy productivity acts as an exogenous variable only for the municipal waste recycling rate, while the water productivity acts as an exogenous variable for the domestic material consumption, the energy productivity and the annual growth rate of national nominal net product, being an endogenous variable only in relation to the water exploitation index. On the other hand, the water exploitation index, as one of the specific variables of circular economy, as previously highlighted, is found in a co-integration relationship as an exogenous variable with five of the other eight variables considered without being influenced by any of them. At the same time, one of the remarkable results is that carbon dioxide emissions are significantly influenced by the resources productivity, under a negative correlation, and by the municipal waste recycling rate, under direct correlation. As deriving from the results obtained in this research, the Romanian economy has the potential of paradigm transformation, thus eventually acquiring a circular character. Beyond the transformation of the national economy paradigm, the added economic value that the circular economy can create through its environmental and social dimensions is mainly worth considering, thus developing the potential to regenerate components and structures of the economy by promoting sustainable consumption and reducing the energy footprint and the pressure on natural capital.

DOI: $10.24818 / 18423264 / 52.2 .18 .08$ 
Developments of the Circular Economy in Romania under the New Sustainability Paradigm

\section{REFERENCES}

[1] Abdullah, S. and Morley, B. (2014), Environmental Taxes and Economic Growth: Evidence from Panel Causality Tests; Energy Economics, 42, pp. 27-33. doi: 10.1016/j.eneco.2013.11.013;

[2] Andrei, J. V.et al. (2016), The Impact and Determinants of Environmental Taxation on Economic Growth Communities in Romania; Energies, 9(11), p. 902. doi: 10.3390/en9110902;

[3] Apergis, N. and Payne, J. E. (2010), Energy Consumption and Growth in South America: Evidence from a Panel Error Correction Model; Energy Economics, 32(2010), pp. 1421-1426. doi: 10.1016/j.eneco.2010.04.006;

[4] Arellano, M. and Bover, O. (1995), Another Look at the Instrumental Variable Estimation of Error-components Models; Journal of Econometrics, 68(1), pp. 29-51. doi: 10.1016/0304-4076(94)01642-D;

[5] Baltagi, B. H. (2005), Econometric Analysis of Panel Data. Third Edition. West Sussex: John Wiley \& Sons Ltd.;

[6] Bond, S. (2002), Dynamic Panel Data Models: A Guide to Micro Data Methods and Practice. London. Available at: http://www.cemmap.ac.uk/wps/cwp0209.pdf (Accessed: 25 May 2017);

[7] Choi, I. (2001), Unit Root Tests for Panel Data; Journal of international money and finance, 20(2), pp. 249-272;

[8] Crépin, A.-S. et al. (2012), Regime Shifts and Management; Ecological Economics, 84(December 2012), pp. 15-22. doi: 10.1016/j.ecolecon.2012.09.003;

[9] Engle, R. F. and Granger, C. W. J. (1987), Co-Integration and Error Correction: Representation, Estimation and Testing; Econometrica, 55(2), pp. 251-276;

[10] Eurostat (2017) Eurostat Database. Available at: http://ec.europa.eu/eurostat/data/database (Accessed: 7 July 2017);

[11] Granger, C. W. J., Huangb, B.-N. and Yang, C.-W. (2000), A Bivariate Causality between Stock Prices and Exchange Rates: Evidence from Recent Asianflu; The Quarterly Review of Economics and Finance, 40(3), pp. 337354. doi: 10.1016/S1062-9769(00)00042-9;

[12] Huppes, G. and Ishikawa, M. (2009), Eco-efficiency Guiding Micro-level Actions towards Sustainability: Ten Basic Steps for Analysis; Ecological Economics, 68(6), pp. 1687-1700. doi: 10.1016/j.ecolecon.2009.01.007;

[13] Im, K. S., Lee, J. and Tieslau, M. (2010), Panel LM Unit Root Tests with Trend Shifts; SSRN Electronic Journal. doi: 10.2139/ssrn.1619918;

[14] Im, K. S., Pesaran, M. H. and Shin, Y. (2003), Testing for Unit Roots in Heterogeneous Panels; Journal of Econometrics, 115(1), pp. 53-74. doi: 10.1016/S0304-4076(03)00092-7;

DOI: $10.24818 / 18423264 / 52.2 .18 .08$ 
Mihaela Cristina Drăgoi, Maria-Floriana Popescu, Jean Vasile Andrei, Mihai Mieilă

[15] Kalmykova, Y., Sadagopan, M. and Rosado, L. (2017), Circular Economy From Review of Theories and Practices to Development of Implementation Tools; Resources, Conservation and Recycling. doi: 10.1016/j.resconrec.2017.10.034;

[16] Kirchherr, J., Reike, D. and Hekkert, M. (2017), Conceptualizing the Circular Economy: An Analysis of 114 Definitions; Resources, Conservation and Recycling, 127(December 2017), pp. 221-232. doi: 10.1016/j.resconrec.2017.09.005;

[17] Korhonen, J., Honkasalo, A. and Seppälä, J. (2018), Circular Economy: The Concept and its Limitations; Ecological Economics, 143(January 2018), pp. 3746. doi: 10.1016/j.ecolecon.2017.06.041;

[18] Levin, A., Lin, C.-F. and James Chu, C.-S. (2002), Unit Root Tests in Panel Data: Asymptotic and Finite-sample Properties; Journal of Econometrics, 108(1), pp. 1-24. doi: 10.1016/S0304-4076(01)00098-7;

[19] Lewandowski, M. (2016), Designing the Business Models for Circular Economy-Towards the Conceptual Framework; Sustainability, 8(1), p. 43. doi: 10.3390/su8010043;

[20] Lifset, R. and Graedel, T. E. (2002), Industrial Ecology: Goals and Definitions. Available at:

http://planet.botany.uwc.ac.za/nisl/ESS/Documents/Industrial_Ecology_Overvie w.pdf (Accessed: 10 August 2017);

[21] Lovins, A., Hawken, P. and Lovins, H. (2008), Natural Capitalism: Creating the Next Industrial Revolution. First Edition. New York, NY: Natural Capitalism: Creating the Next Industrial Revolution;

[22] Martins, N. O. (2018), The Classical Circular Economy, Sraffian Ecological Economics and the Capabilities Approach; Ecological Economics, 145(March 2018), pp. 38-45. doi: 10.1016/j.ecolecon.2017.08.026;

[23] Pesaran, M. H. (2007), A Simple Panel Unit Root Test in the Presence of Cross-section Dependence; Journal of Applied Econometrics, 22(2), pp. 265312. doi: 10.1002/jae.951;

[24] Phillips, P. C. B. and Ouliaris, S. (1990), Asymptotic Properties of Residual Based Tests for Cointegration; Econometrica, 58(1), p. 165. doi: 10.2307/2938339;

[25] Popescu, G. H. et al. (2018), The Emergence of the Effects and Determinants of the Energy Paradigm Changes on European Union Economy; Renewable and Sustainable Energy Reviews, 81(Part 1), pp. 768-774. doi: 10.1016/j.rser.2017.08.055. 